\title{
Estudo de Fungos Queratinofílicos Geofílicos em Praças Públicas de Jaboticabal-SP
}

\author{
Adilson César Abreu Bernardi* \\ Juliana Leal Monteiro da Silva* \\ Ana Paula Gomes Souto** \\ Camila Chioda de Almeida**
}

\section{RESUMo}

Considerando o uso das praças públicas como recurso de lazer pela população, as quais mantêm um contato intenso e direto com o solo, que é uma fonte potencial de contaminação por diferentes agentes causadores de micose, visou-se identificar gêneros de fungos queratinofílicos geofílicos no solo de praças de Jaboticabal SP. Foram selecionadas e coletadas 60 amostras de solo de 15 praças públicas, sendo 4 amostras de cada praça. Para isolar os fungos do solo, foi utilizado o método de Vanbreuseghem (1952), modificado por Machado (1977). Posteriormente os fungos foram cultivados em placas de Petri contendo Agar Sabouraud acrescido de Cloranfenicol, sendo estas incubadas em temperatura ambiente por aproximadamente dez dias. As colônias crescidas foram isoladas em tubos de ensaio para obtenção de cultura pura. Foram feitas análises macroscópicas e microscópicas das colônias isoladas, identificadas em nível de gênero com o auxílio de um guia de identificação. Das 60 amostras de solo coletadas, 39 apresentaram positividade para fungos queratinofílicos, das quais foram isoladas 90 colônias fúngicas, sendo identificados os gêneros Penicillium spp., Fonsecaea spp., Rhizopus spp., Microsporum spp., Fusarium spp., Phialophora spp., Aspergillus spp., Acremonium spp., Nigrospora spp., Trichoderma spp., Bipolaris spp., Aureobasidium spp., Curvularia spp., Mucor spp., além de Mycelia sterilia. Os resultados permitiram concluir que estes solos representam uma microbiota diversificada com capacidade de degradar substratos de queratina,

\footnotetext{
*Docentes do Centro Universitário de Araraquara - Uniara. Mestres e doutores em Biociências e Biotecnologia Aplicadas à Farmácia (Unesp).

**Biólogas formadas pelo Centro Universitário de Araraquara - Uniara (apgsouto@ hotmail.com; milachioda@hotmail.com)
} 
permitindo uma avaliação do potencial epidemiológico representado pelos solos nas praças do Município de Jaboticabal-SP.

Palavras-chave: Fungos filamentosos; Fungos queratinofílicos; Fungos geofílicos; Praças públicas; Micoses.

\section{INTRODUÇÃo}

A micologia ou micetologia é o ramo da Biologia que estuda os fungos, micetos ou cogumelos, enquadrados em um reino bem definido, denominado Reino Fungi (LACAZ et al., 2002).

Os fungos habitam os mais variados substratos. A maioria das espécies vive no solo, tendo um importante papel, ao lado de outros organismos, na reciclagem dos materiais na natureza (ZAITZ et al., 1998). Quanto ao ecossistema em que vivem, os fungos podem fazer uso de fontes nutricionais de três formas diferenciadas: como sapróbios, simbiontes ou parasitas (SIDRIM; MOREIRA, 1999).

No parasitismo, apenas um dos seres vivos tira proveito da relação, havendo prejuízo para aquele que é parasitado. São exemplos clássicos de parasitismo as infecções humanas e animais causadas por fungos, conhecidas popularmente como micoses, palavra derivada do grego, onde mykes [mic(o)] refere-se a fungo e osis (ose) à ação (SIDRIM; MOREIRA, 1999).

Dentre os agentes etiológicos das micoses mais conhecidas, destacam-se os fungos queratinofílicos, que se apresentam na forma filamentosa, podendo ser dimórficos. Têm seu habitat em substratos queratinizados, alguns deles possuindo a capacidade de degradar a queratina, denominando-se então, fungos queratinolíticos (KUNERT, 2000). A maioria pode parasitar tecidos queratinizados do homem e de outros animais, comportando-se em alguns casos como fungos patógenos (dermatófitos), causadores de dermatofitoses.

Utilizando o método de Vanbreuseghem descrito em 1952, vários trabalhos têm demonstrado que o solo é um importante reservatório para muitos desses fungos, isolando-se numerosas formas perfeitas ou teleomórficas (fase sexuada), tendo algumas delas fases anamórficas (assexuada) de espécies de fungos dermatófitos. Santos, Lima e Philippi (2007), investigando a contaminação ambiental por fungos queratinofílicos no solo do campus da Universidade Federal de Santa Catarina (UFSC) e de escolas, praças e parques de bairros residenciais, localizados no seu entorno, na cidade de Florianópolis-SC, verificaram a presença de Microsporum gypseum em 22 do total de 29 amostras de solo. Outros fungos não dermatófitos observados foram Trichoderma sp., Penicillium sp., Cladosporium sp., Mucor sp. e Rhodotorula sp. Souza e Araújo (2007), 
isolando fungos queratinofílicos do solo de parques de recreação de instituições de ensino de Maceió-AL, encontraram os seguintes gêneros: Aspergillus sp. 5 (6,25\%), Penicillium sp. 4 (5\%), Fusarium sp. 2 (2,5\%), Acremonium sp. 2 (2,5\%), Chrysosporium sp. 1 (1,25\%), Sincephalastrum sp. 1 (1,25\%) e Verticillium sp. 1(1,25\%). Mangiaterra et al. (1998) analisaram 180 amostras de solo dos departamentos de San Fernando e General San Martín, Chaco, Argentina, encontrando entre eles: Microsporum gypseum-fulvun (44\%), Aphanoascus fulvenscens (36,6\%), Chysosporium indicum (31,1\%), Myceliophthora vellera (32,8\%), Gymnascella aurantiaca (18,9\%), Uncinocarpus reesii (14,4\%), Chysosporium tropicum (13,9\%), Chysosporium keratinophilum $(11,1 \%)$, Trichophyton terrestre $(11,1 \%) \mathrm{e}$ cepas de Malbranchea sp. (11,6\%).

Considerando o uso de praças públicas como recurso de lazer por algumas pessoas, as quais mantêm um contato intenso e direto como solo, este se torna uma fonte potencial de contaminações por diferentes agentes causadores de micoses. Nesse contexto, visa-se conhecer a diversidade de fungos queratinofílicos presentes em praças públicas de Jaboticabal-SP.

\section{Materiais e MÉtodos}

Foram selecionadas e coletadas, com o auxílio de coletor universal e uma colher esterilizados, 60 amostras de solo de 15 praças públicas - 4 de cada praça. Para isolar os fungos do solo, foi utilizado o método de Vanbreuseghem (1952), modificado por Machado (1977). Posteriormente, os fungos foram cultivados em placas de Petri contendo Agar Sabouraud acrescido de Cloranfenicol, sendo estas incubadas em temperatura ambiente por aproximadamente dez dias. As colônias crescidas foram isoladas em tubos de ensaio, contendo Agar Sabouraud para obtenção de cultura pura.

Após obtenção da cultura pura, as colônias foram analisadas quanto às suas características macroscópicas - tamanho, borda, textura, relevo e pigmentação - e microscópicas, realizadas após preparo com corante Lactofenol Azul-algodão e observadas ao microscópio óptico entre lâmina e lamínula. Todas as colônias foram identificadas nessa fase em nível de gênero, com o auxílio de um guia de identificação, não sendo necessário utilizar a técnica do microcultivo.

\section{ReSUltados}

Foram isoladas um total de 60 amostras de solo de 15 praças públicas, das quais $39(65 \%)$ foram positivas para fungos queratinofílicos e 21 (35\%) negativas, como mostra o Gráfico 1. 


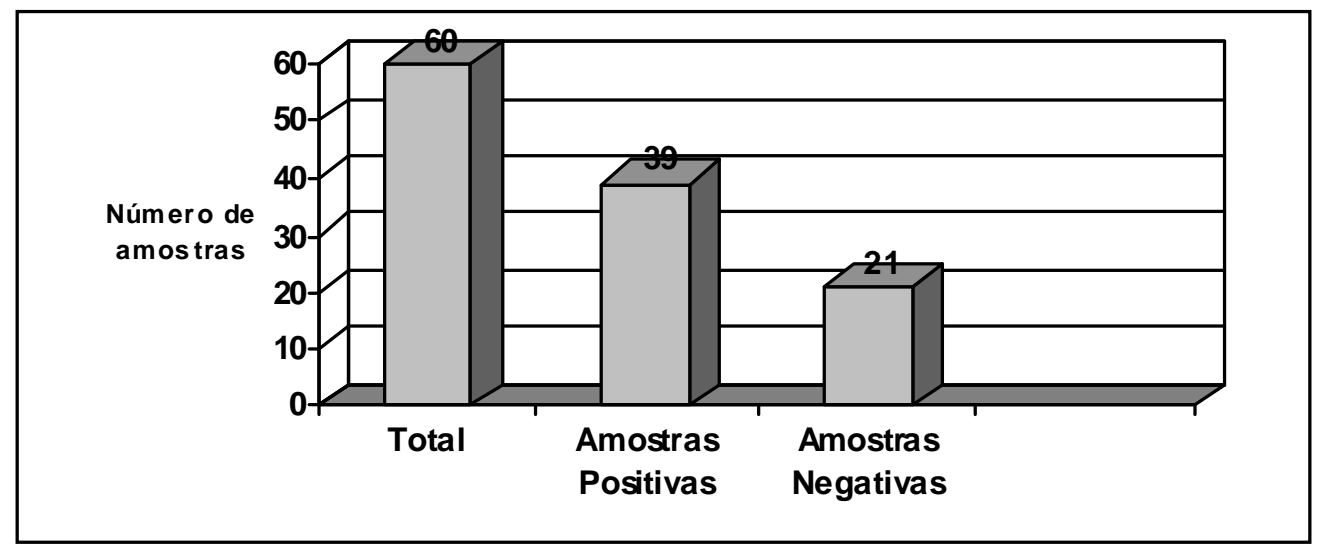

Gráfico 1. Amostras negativas e positivas de fungos queratinofílicos nas 60 amostras.

Das 39 amostras positivas para a presença de fungos, foram isoladas 90 colônias fúngicas, sendo 3 na Praça Joaquim Batista (3,33\%), 3 na Praça Dom Assis (3,33\%), 4 na Praça Duílio Poli (4,44\%), 2 na Praça Julio Zocolaro (2,22\%), 3 na Praça José Talarico (3,33\%), 6 na Praça Nove de Julho (6,66\%), 16 na Praça Felício Buzaid (17,77\%), 7 na Praça Silvio Borsari (7,77\%), 9 na Praça Santo Marconato (10\%), 7 na Praça Cohab I (7,77\%), 8 na Praça Esplanada do Lago (8,88\%), 7 na Praça Joaquim Nabuco (7,77\%), 11 na Área Institucional Jardim das Rosas (12,22\%), 2 na Praça Bairro Residencial (2,22\%) e 2 na Praça Parque dos Laranjais $(2,22 \%)$, conforme demonstrado no Gráfico 2. 


\section{Total de Colônias Isoladas = Praça Joaquim Batista}

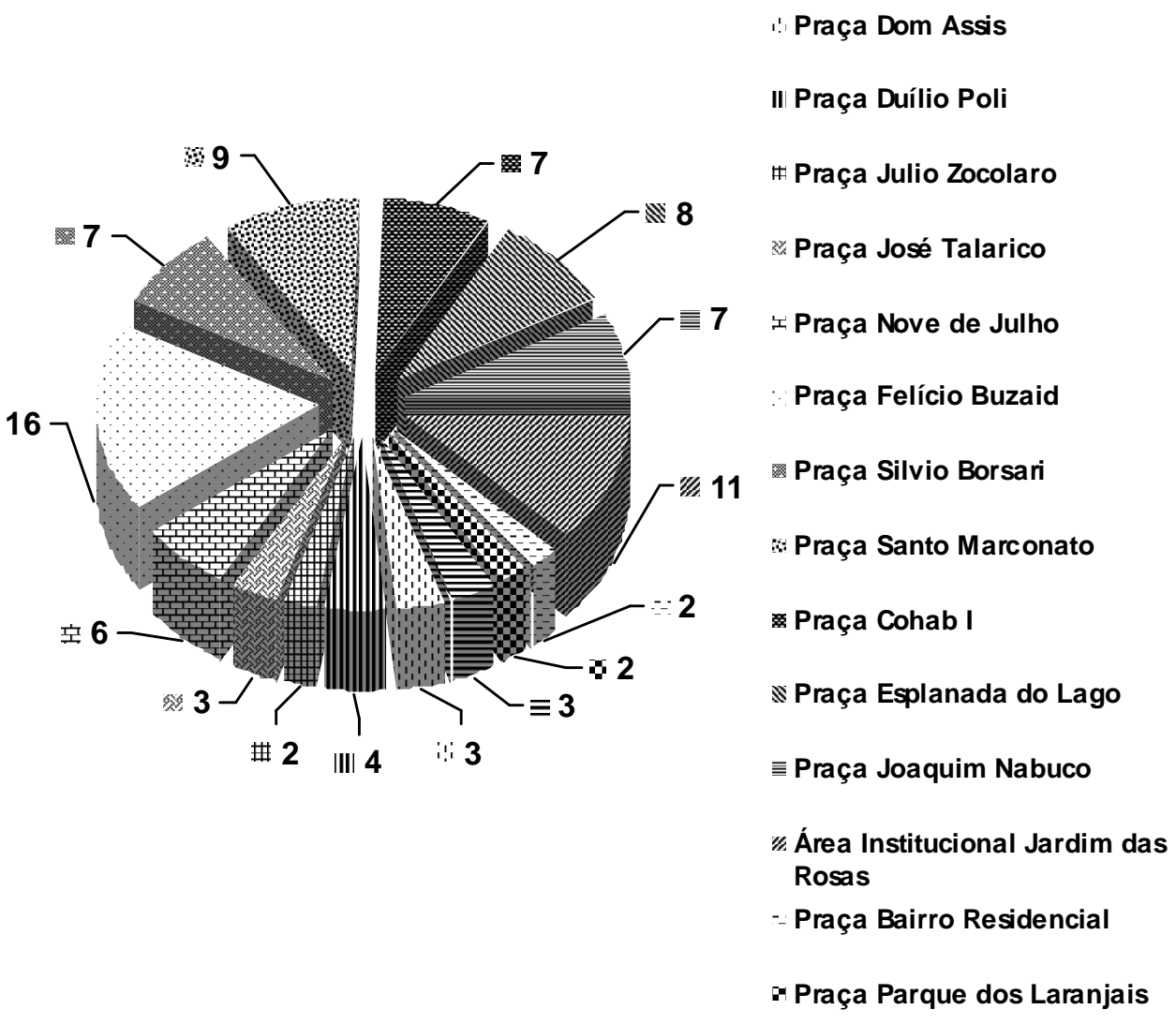

Gráfico 2. Total de colônias isoladas das amostras coletadas por praça.

Das 90 colônias isoladas, foram identificadas 31 colônias de Mycelia sterilia (34,4\%), 12 de Penicillium sp. (13,3\%), 12 de Fonsecaea sp. (13,3\%), 11 de Rhizopus sp. (12,2\%), 5 de Microsporum sp. (5,5\%), 5 de Fusarium sp. (5,5\%), 3 de Phialophora sp. (3,3\%), 2 de Aspergillus sp. (2,2\%), 2 de Acremonium sp. (2,2\%), 2 de Nigrospora sp. (2,2\%), 1 de Trichoderma sp. (1,1\%), 1 de Bipolaris sp. (1,1\%), 1 de Aureobasidium sp. (1,1\%), 1 de Curvularia sp. $(1,1 \%)$ e 1 de Mucor sp. (1,1\%), conforme mostra o Gráfico 3. 


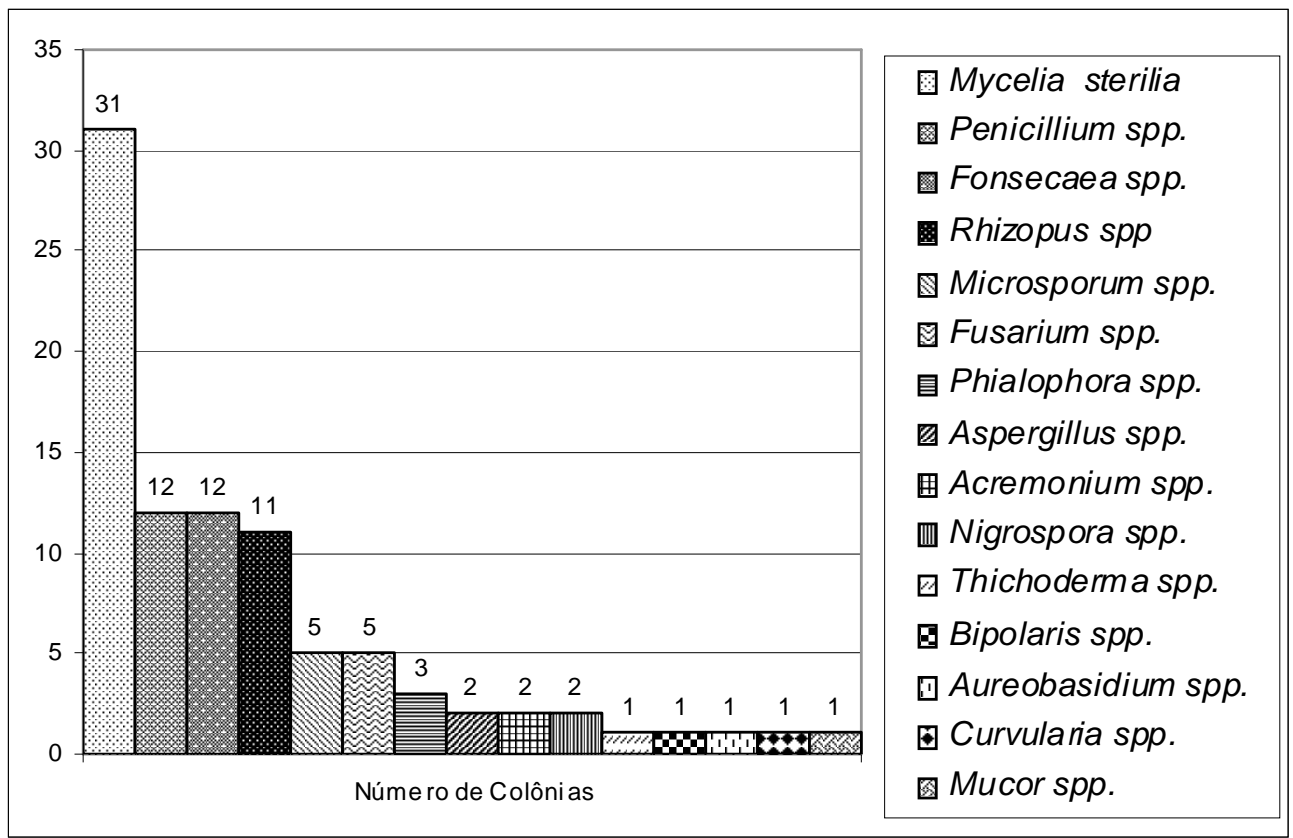

Gráfico 3. Gêneros de fungos identificados nas 90 amostras.

A Figura 1 representa a microscopia dos 15 gêneros de fungos encontrados nas colônias isoladas.

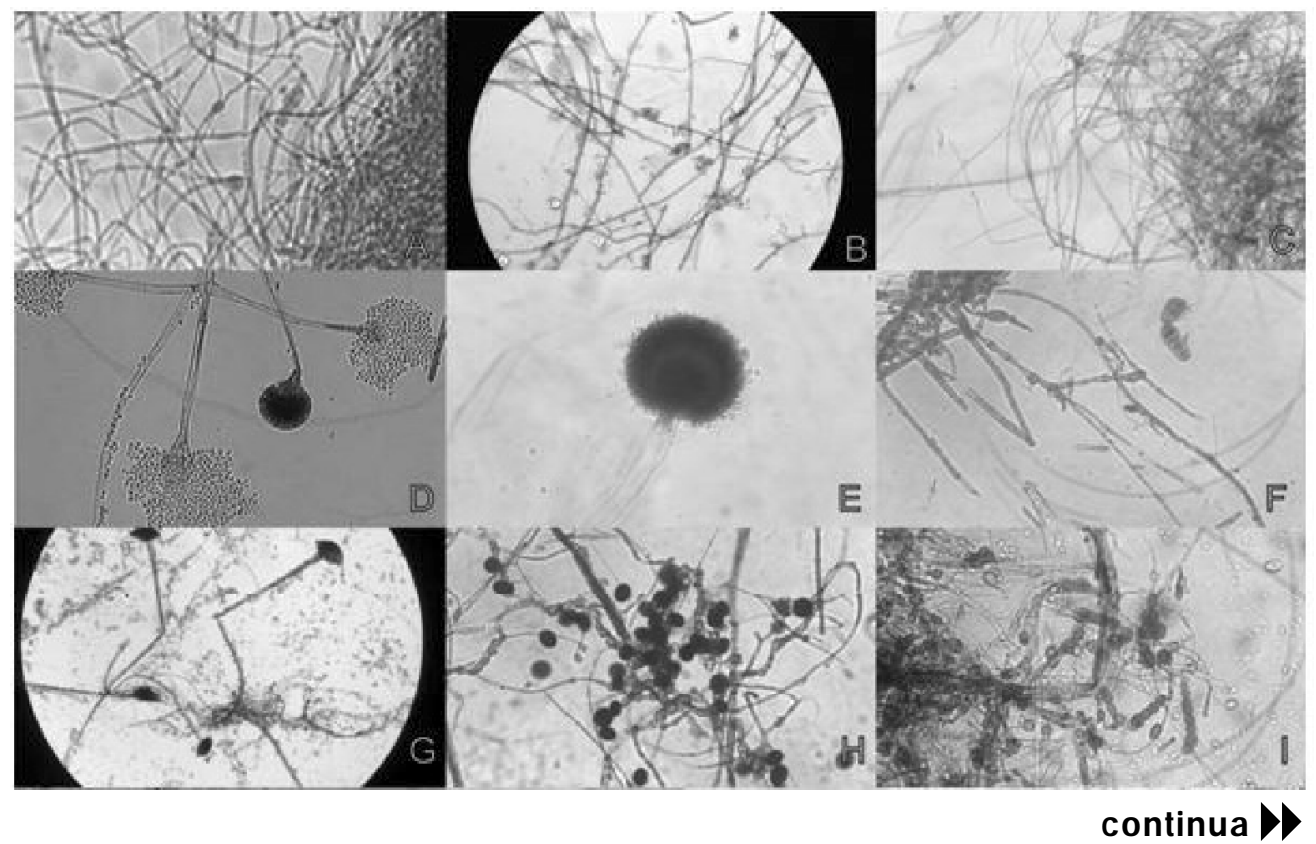




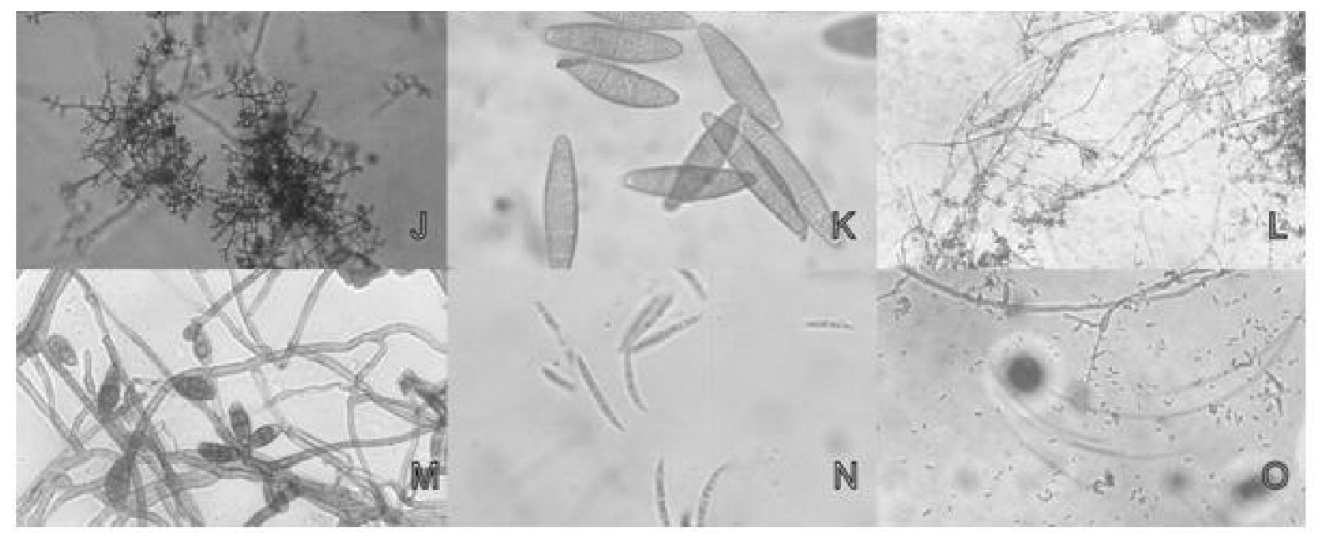

Figura 1. Microscopia dos fungos identificados: A) Mycelia sterilia; B) Fonsecaea sp.; C) Phialophora sp.; D) Mucor sp.; E) Aspergillus sp.; F) Bipolaris sp.; G) Rhizopus sp.; H) Nigrospora sp.; I) Aureobasidium sp.; J) Trichoderma sp.; K) Microsporum sp.; L) Penicillium sp.; M) Curvularia sp.; N) Fusarium sp.; O) Acremonium sp.

\section{Discussão}

Mello, Ribeiro e Fortes (2007) descreveram que o solo é o habitat de um imenso número de espécies de microrganismos, dentre eles os fungos, cuja dispersão é feita pelo homem, animais, água e ar atmosférico, demonstrando seu caráter cosmopolita. Dentre os tipos de solo, a terra é um reservatório desses organismos, incluindo os fungos queratinofilicos, encontrados na natureza nos estágios finais da decomposição de carapaças, cascos, pele, pelo ou penas; além disso, têm habilidade de invadir os tecidos mais superficiais queratinizados do homeme outros animais, causando diferentes quadros clínicos de infecção cutânea (dermatomicose) e eventualmente subcutânea.

Nesta pesquisa, com o objetivo de demonstrar as ocorrências de fungos queratinofílicos em praças da cidade de Jaboticabal-SP, foi observado que há um grande número de fungos saprófitas e alguns com perfil de patogenicidade (dermatomicoses) e processos alérgicos (micotoxinas) (Gráfico 3).

A qualidade ambiental das praças é de grande importância para a saúde pública, pois o solo contaminado pode transmitir inúmeras doenças causadas por diversos parasitas, entre esses os fungos.

Ferreira et al. (2007) e Mello, Ribeiro e Fortes (2007) pesquisaram fungos filamentosos queratinofilicos pelo método de iscagem usando fios de cabelos estéreis.

Nesta pesquisa também foi utilizado o método e, das 60 amostras estudadas, 39 foram positivas para a pesquisa desses fungos.

Os fungos queratinofílicos, principalmente os dermatófitos, são agentes das 
dermatomicoses, distúrbios de pele mais comuns no mundo.

Foram isolados e identificados em três praças cinco colônias da espécie Microsporum gypseum, fungo dermatófito geofilico que pode causar dermatomicoses em seres humanos e animais, representando importante fonte de contaminação ambiental e humana. Amaral, Conci e Severo (1989) descreveram um surto de tinha da pele glabra ocasionado pelo Microsporum gyspeum, caracterizando como fonte da infecção uma caixa de areia em que brincavam as crianças.

Souza e Araújo (2007) e Mello, Ribeiro e Fortes (2007) isolaram pelo método de isca os fungos identificados como Aspergillus sp., Penicillium sp., Fusarium sp., Acremonium sp., Chrysosporium sp., Sincephalastrum sp. e Verticillium sp.

Em nossa pesquisa também isolamos os fungos Aspergillus sp. (agente etiológico de aspergilose), Penicillium sp. (geralmente não patogênico, algumas espécies produzem micotoxinas), Fusarium sp. (agente etiológico de oftalmomicoses, ceratites, onicomicoses) e Acremonium sp. (agente de infecção oportunista).

Outros gêneros foram identificados neste trabalho, como: Fonsecaea sp. (agente etiológico de cromomicoses), Rhizopus sp.(agente etiológico de zygomycoses), Microsporum sp. (agente etiológico de dermatomicoses), Phialophora sp. (agente etiológico de ceratite, cromomicoses, absessos subcutâneos), Nigrospora sp. (patógeno de plantas e do solo), Trichoderma sp. (produtor de micotoxinas), Bipolaris sp. (agente de feo-hifomicoses), Aureobasidium sp., Curvularia sp. (agente de lesões cutâneas) e Mucor sp. (agente de lesões cutâneas).

O gênero Mycelia sterilia foi o mais isolado pelo seu perfil característico (facilidade de crescimento e propagação). Menezes et al. (2004) descreveram o gênero como causador de alergias respiratórias (asma e rinite).

\section{Conclusão}

Concluímos, com os resultados, que estes solos representam uma microbiota diversificada, com capacidade de degradar substratos de queratina, permitindo uma avaliação do potencial epidemiológico representado pelos solos nas praças do município de Jaboticabal-SP.

\section{REFERÊNCIAS}

AMARAL, A. A.; CONCI, L. M. A.; SEVERO, L. C. Microsporum gypseum- Relato de surto de infecção e isolamento do solo. An.Bras.Dermatol., Porto Alegre, v. 64, n. 2, p. 119-120, 1989.

FERREIRA, L. S.; COSTA, P. F.; MONTEIRO, W. P.; MESQUITA, R. C. 
Isolamento de fungos filamentosos queratinofilicos emareias de praias nailha de Mosqueiro-Belém-PA. In: 59 Reuniao Anual da Sociedade Brasileira para o Progresso da Ciência, 2007, Belém. Anais..., 2007.

KUNERT, J. Physiology of keratinophilic fungi. In: Biology of Dermatophytes and other Keratinophilic Fungi. Revista Iberoamericana de Micologia. Bilbao.p. 77-85. 2000.

LACAZ, C. S.; PORTO, E.; MARTINS, J. E. C.; HEINS-VACCARI, E. M.; MELO, N. T. Tratado de micologia médica. ed. 9. São Paulo: Sarvier. 2002.

MACHADO, O. P. Ocorrência de dermatófitos em solos no Município de Goiânia-Goiás. Ver. Pat. Trop., 6: 43-67, 1977.

MANGIATERRA, M.;PIONTELLI, E.; GIUSIANO, G.; GRIZOLLI, M.A.; ALONSO, J. M. Geohongos queratinofílicos de los departamentos San Fernando y Gral. San Martín, Chaco-Argentina. Boletín micológico. v. 13. p. 77-84. Universidad de Valparaiso. Facultad de Medicina 1998.

MELLO, M. P. M. ; RIBEIRO, T. P. S. ; FORTES, S. T. . Fungos Queratinofilicos isolados de areia de parques escolares emBoas Vista-RR. In: Encontro de Pesquisa e Iniciação Ciêntifica da UFRR, 2007. Boa Vista - RR. CD do encontro. 2007.

MENEZES, E. A.; CARVALHO, P. G.; TRINDADE, E. C. P. M.; SOBRINHO, G. M.; CUNHA, F. A.; CASTRO, F. F. M. Fungos anemófilos causando alergia respiratória em pacientes na cidade de Fortaleza, Ceará. J. Bras. Patol. Med. Lab. v. 40. n.2.p. 79-84. abr. 2004. Disponívelem: < http://www.scielo.br/ scielo.php?pid=S1676-24442004000200006\&script=sci_abstract\&tlng=pt $>$. Acesso em: 13 set. 2009.

SANTOS, J. I. dos, LIMA, L. M., PHILIPPI, J. M. de S. Pesquisa de helmintos e isolamento de fungos queratinofilicos em amostras de solo do Campus da UFSC e de bairros residenciais próximos ao Campus. In: SEMANA DEENSINO, PESQUISAE EXTENSÃO, 6. Anais eletrônicos... Universidade Federal de Santa Catarina., 2007. Disponívelem: < http://www.sepex.ufsc.br/anais_6/trabalhos/547.html >.Acesso em: 10 ago. 2009.

SIDRIM, J. J. C.; MOREIRA, J. L. B. Fundamentos clínicos e laboratoriais da micologia Médica. Rio de Janeiro: Guanabara Koogan, 1999. 
SOUZA, A. K. P.; ARAUJO, M. A. S. Isolamento de fungos queratinofílicos do solo de praças e areia de praia do município de Maceió, Alagoas. In: Congresso Brasileiro de Micologia, 2007, Recife. Micologia Avanços no Conhecimento. Recife-PE: Universitária daUFPE, 2007. v. 5.p. 5-376. 2007.

VANBREUSEGHEM, R. Technique biologique pour I isolement des dermatophytes du sol. Ann Soc Belge Med Trop, 32: 173-178,1952

\section{ZAITZ, C.; MARQUES, S. A.; RUIZ, L. R. B.; SOUZA, V. Mde. Compêndio de micologia médica. Rio de Janeiro: MEDSI, 1998.}

\section{Title: Study of Geophilic Keratinophilic Fungi in Public Squares of JABOTICABAL-SP}

\section{ABSTRACT}

Considering the use of public parks as a source of leisure for the population, who maintain an intense and direct contact with the ground, which is a potential source of contamination by different causative agents of mycosis, the purpose of the research was to identify genera of keratinophilic geophilic fungi in the soil of squares in Jaboticabal-SP. 60 soil samples from 15 public squares, and 4 samples of each square were selected and collected. To isolate the soil fungi, we used the method of Vanbreuseghem (1952), modified by Machado (1977). Later the fungi were cultivated in Petri dishes containing Sabouraud Agar added to chloramphenicol, and were incubated at room temperature for about ten days. The grown colonies were isolated in test tubes to obtain pure culture. Macroscopic and microscopic analyses of isolated colonies were made and they were identified at a gender level with the aid of an identification guide. From 60 soil samples collected, 39 were positive for keratinophilic fungi, of which 90 fungic colonies were isolated, being identified the genera Penicillium spp. Fonsecaea spp., Rhizopus spp., Microsporum spp., Fusarium spp., Phialophora spp., Aspergillus spp., Acremonium spp., Nigrospora spp., Trichoderma spp., Bipolaris spp., Aureobasidium spp., Curvularia spp., Mucor spp. and Mycelia sterilia. The results allowed us to conclude that these soils represent a diverse microflora capable of degrading keratin substrates, allowing an assessment of the epidemiological potential represented by the soil in the squares of the city of Jaboticabal-SP.

KEYWords: Filamentous fungi; Keratinophilic fungi; Geophilic fungi; Public squares; Mycoses. 